\title{
Risk Factors for Infantile Recurrent Otitis Media: Atopy but Not Type of Feeding
}

\author{
V-M. TAINIO, E. SAVILAHTI, L. SALMENPERÄ, P. ARJOMAA, M. A. SIIMES, AND \\ J. PERHEENTUPA \\ Children's Hospital, University of Helsinki, Helsinki, Finland
}

\begin{abstract}
We followed 183 infants from birth to $2.3 \mathrm{yr}$ of age. Of these infants 28 had recurrent otitis media (ROM), defined as five or more separate episodes of otitis media (OM) during the first 2 yr of life or four such episodes during their 2 nd $y r$. The $O M$ presented during their 1st yr (early-onset ROM) in 12 infants and during their 2nd yr (2nd yr ROM) in 16. Eighty infants had no $O M$ and served as a comparison group. Regarding type of feeding, the infants with early-onset ROM did not differ from their age-matched pairs in the comparison group either 1 month before the first $O M$ or at the time of first episode of OM. Exclusive breast-feeding did not prevent OM and early weaning was not a risk factor for ROM. Atopy was associated with ROM with a relative risk of $1.9(95 \%$ confidence limits $1.2-3.2)$. It was particularly prevalent among the infants with early-onset ROM, in 67 versus in $25 \%$ in the comparison group $(p<0.01)$. During the 2 nd yr daily contact with five or more children was associated with ROM with a relative risk of 2.1 (1.3-3.3). The infants with 2 nd-yr ROM were in daily contact with more children than the comparison group (mean 11 versus $5 ; p<0.001$ ). Parental smoking was more frequent among the infants with ROM than in the comparison group (54 versus $33 \% ; p<0.05$ ). In the infants with early-onset ROM plasma concentration of IgM antibodies to cow's milk was highest at the age of 9 months, and the concentration of IgE was highest at the ages of 9 and 12 months. In conclusion atopy, not the type of feeding, is a risk factor for early-onset ROM, and daycare outside the home for ROM during the 2nd yr. (Pediatr Res 23: 509-512, 1988)
\end{abstract}

\section{Abbreviations}

OM, otitis media

ROM, recurrent otitis media

CM, cow's milk

CMA, cow's milk allergy

OM may occur in early infancy, but its incidence increases rapidly after the age of 6 months $(1,2)$. In a Finnish follow-up study $5 \%$ of infants had OM during the first 6 months of life, $36 \%$ during their $1 \mathrm{st} \mathrm{yr}$, and $59 \%$ during their 2 nd and $3 \mathrm{rd} \mathrm{yr}$ (3). Several risk factors have been identified: daycare outside the home (4), enlarged adenoids (5), feeding in the horizontal position (6), smoking at home (7), and atopy $(8,9)$, particularly food allergy (9). Some studies suggest a protective effect of breast-

Received June 16, 1987; accepted January 12, 1988

Correspondence, V-M Tainio, Children's Hospital, University of Helsinki, 00290 Helsinki, Finland.

Supported by grants from the Sigrid Juselius Foundation, the Foundation for Pediatric Research and the Foundation for Nutrition Research, Helsinki, Finland. feeding $(3,10,11)$ but others detect none $(2,13)$. Any study of the impact of feeding on morbidity is beset with numerous methodologic limitations (14).

In this prospective study we followed 198 infants throughout the 1st yr of life, carefully recording their feeding regimen, illnesses, and environment. For 183 of the infants similar data were obtained from the parents regarding the 2 nd yr by a detailed questionnaire. From these data we analyzed the risk factors for ROM.

\section{MATERIALS AND METHODS}

We followed 198 healthy newborns from birth; they were seen at clinic visits at $2,4,6,9$, and 12 months of age, and whenever they had any problems regarding feeding, nursing, or illness. At a mean age of 2.3 yr 60 of the infants were examined by one of us (V-M.T.), and a questionnaire was sent to each family. The questionnaire was returned by 183 families. Data concerning health, feeding, and socioenvironmental factors were recorded at each visit and from the questionnaire (15-17). All medical care during the 1 st year was provided by one pediatrician (L.S.). The illnesses during the $2 \mathrm{nd}$ yr were treated by physicians chosen by the parents. The services of health center physicians are free of charge. General health insurance covers part of the fees of private practioners, and additional voluntary insurance usually covers such fees completely. Therefore parents seek medical care for their infants very readily, and pediatric and otologic services are commonly used. A venous blood sample was taken at each clinic visit, and levels of plasma IgE and cows' milk antibodies were measured (15-17). The plasma levels of IgG and IgM CM antibodies are expressed as percentages of a standard plasma with a high level of CM antibodies.

OM was defined as an otoscopic loss of translucency and landmarks, clear inflammation or bulging of, lack of mobility of, or purulent discharge from the tympanic membrane. Infants with OM or ROM were symptomatic.

ROM was defined as the number of separate episodes of OM occurring in the 90th percentile of the whole series of infants during the first $2 \mathrm{yr}$ (five episodes), or in the 95th percentile during the 2 nd yr (four episodes). An OM occurring 2 months after a previous $\mathrm{OM}$ and after a normal otoscopic finding during the interval was regarded as a separate episode. Early-onset ROM was ROM with the first OM during the 1st yr, and 2nd-yr ROM was ROM with first OM during the 2 nd yr.

Atopy. The diagnosis was based on the presence of pruritic dry dermatitis, urticarial eruption, three or more episodes of wheezy bronchitis, or three of the following: rhinorrhea lasting more than 1 month, frequent itching and/or watering of the eyes, two episodes of wheezy bronchitis, gastrointestinal symptoms provoked by foods (16). The most frequent problems were cutaneous.

CMA was diagnosed if skin, respiratory, or gastrointestinal signs developed repeatedly after ingestion of cow's milk and 
disappeared on a cow's milk-free diet, and were provoked by a cow's milk challenge test at hospital.

Feeding. All mothers were encouraged to breast-feed as long as possible. Of the 198 infants, 32 were completely weaned by 3.5 months of age. At 6 months of age 101 and at 9 months 31 infants were still exclusively breast-fed, having no milk formula or other complementary food. The weaned infants followed a standard dietary program including an adapted formula (Tutteli, Valio, Ltd Helsinki; protein concentration $16 \mathrm{~g} / \mathrm{liter}$ ), fruit and vegetables from 3 months of age, and cereals and meat from 5 months. Pasteurized whole cow's milk was substituted for the formula from 9 months. For 98 infants, the most frequent food allergens (eggs, fish, tomatoes, citrus fruit, chocolate, peas, and strawberries) were excluded from the diet until 12 months of age, on the advice given by well baby clinics to the families with a history of atopy.

Socioeconomic background. Of the mothers, $23 \%$ had an academic background and another 39\% had some other form of higher education; $65 \%$ were employed until shortly before the infant's birth, and 38-59\% were employed during the follow-up after a maternity leave of 10 months. By self-assessment the economic status was good in $28 \%$ of the families, satisfactory in $64 \%$, and unsatisfactory in $8 \%$. The mean housing space was 16 \pm 7 (SD) $\mathrm{m}^{2} /$ person. There were three single mothers. In $42 \%$ of the families the infant was the only child, $22 \%$ of families had two children, and $36 \%$ three or more children.

Smoking habits and pets. Of the mothers $15 \%$ and of the fathers $32 \%$ were smokers, and in $36 \%$ of the families either one or both smoked. Smoking took place mainly outside the home. Smoking is forbidden in daycare family homes and daycare centers. A pet was present in $20 \%$ of the homes.

Daycare and contact with other children. At 12 months of age $62 \%$ of the infants were cared for at home by their own mother, $18 \%$ in another family-type arrangement, and $20 \%$ at a public daycare center. At 24 months the respective numbers were 41 , 29 , and $24 \% ; 6 \%$ had another arrangement. The median number of children in home care was two, in the family-type setting four, and at a daycare center 12 .

Statistical analyses. The $\chi^{2}, t$ tests, and multivariate analysis of variance were used for comparisons. Because of skewness of distributions of plasma IgE and cow's milk antibodies, values were analyzed after $\log$ transformation. Predictive factors for ROM and for more than one, two, three, four, or five episodes of OM were searched for by stepwise logistic regression. Seventeen variables were tested. The variables were treated as categorical. Some variables were categorical by nature (variables $6,7,8$, 16 , and 17) and others were divided into two categories either in a way that was relevant for the study (i.e., daycare at home or outside the home) or by choosing a cutoff point using the distribution of the whole series of 183 infants (Table 1).

\section{RESULTS}

$O M$. For the study of ROM, the following groups were distinguished among the series of 183 infants: ROM 28 infants, earlyonset ROM 12 infants, 2nd-yr ROM 16 infants, and a comparison group of 80 infants who had no OM during their first 2 yr. In addition 151 infants had no OM during their 1 st year and 96 during their 2 nd yr. In 14 of the 28 infants with ROM adenoidectomy was done and nine had typanostomy tubes placed. Of the total number of otorhinologic operations in the series, $70 \%$ were in infants with ROM.

Upper respiratory tract infections. The frequency of upper respiratory tract infections was not a risk factor for ROM (Table 1). However, during the 1 st yr such illnesses were more frequent in the infants with ROM than in the comparison group $(6.0 \pm$ 0.6 versus $4.0 \pm 0.2$ infections, $p<0.01$ ). There was no such difference during the 2 nd yr $(2.8 \pm 0.3$ versus $3.4 \pm 0.5$, respectively).

Feeding. None of the feeding variables tested were risk factors

Table 1. Risk factors for infantile ROM*

Relative risk

$+$

(95\% confidence limit)

1. High no. of upper respiratory tract infections ( $\geq 5$ during the first 2 yr of life) $\dagger$

2. Short duration of exclusive breast-feeding ( $\leq 74$ days) $\dagger$

3. Early regular formula feeding (before the age of 99 days $) \dagger$

4. Early complete weaning from breast (before the age of 99 days) $\dagger$

5. Early introduction of solid foods (before the age of 131 days) $\dagger$

6. Positive family history for atopy

7. Occurrence of own atopic disease

8. Occurrence of CMA

9. Low educational level of mother: (no higher education)

10. Low occupational class of mother: (no regular work)

11. Low social class of family: (lowest of 3 classes)

12. Small size of home $\left(\leq 45 \mathrm{~m}^{2}\right) \dagger$

13. Daycare outside the home at the age of $12.0 \mathrm{mo}$

14. High no. of child contacts ( $\geq 5$ during yr 2)

15. Sleeping arrangements (with siblings or parents)

16. Smoking of parents (one or both)

17. Pet at home

* Relative risk is given only where significantly $>1.0$. ROM was defined as $\geq 5$ episodes of $O M$ during the first 2 yr or $\geq 4$ episodes during the 2 nd yr.

$\dagger$ This limit separates one quartile of the study group.

for ROM (Table 1) or for OM (Table 2). The infants with earlyonset or 2nd-yr ROM did not differ from the comparison group in this respect (Tables 3 and 4). The 34 infants with one or more episodes of OM during the 1st yr of life were compared with matched pairs from the comparison group (matched for age, season of birth, smoking of parents, type of daycare, and own atopy) 1 month before the first $O M$ and at the time of first episode of OM. There were altogether three more pairs in whom at the time of the first episode of OM, the infant with OM was weaned more fully than the comparison infant. The infants with early-onset ROM were compared with their matched pairs. Altogether there were no statistical significant differences in these comparisons. Ongoing breast-feeding did not prevent OM; six of the 12 infants with early-onset ROM had the first OM when still exclusively breast-fed and two others when partially breast-fed.

Atopy appeared in 14 infants during the 1st yr and in another 31 during the 2 nd yr. It was associated with a 1.9-fold relative risk of ROM (Table 1) and was more common among the infants with ROM than in the comparison group (50 versus $25 \%, p<$ 0.01 ). The prevalence of atopy was higher among infants with early-onset ROM than in those with 2nd-yr ROM (67 versus $38 \%, p<0.05$ ). The infants with early-onset ROM had the highest concentration of plasma IgE at 9 and 12 months of age (Table 5).

CMA was not a risk factor for ROM (Table 1). Seven infants had cutaneous CMA during the 1 st yr. They tended to have OM more frequently during the $1 \mathrm{st}$ yr than the others $(1.5 \pm 0.6$ versus $0.4 \pm 0.1 ; p<0.1$ ). Only two of these seven infants had no OM during the 1st year versus 145 of the other 186 infants $(p<0.001)$. However, only one of the seven infants with CMA had ROM. 
Table 2. Relative risks (and their $95 \%$ confidence limits) of $O M$ and its recurrence*

\begin{tabular}{|c|c|c|c|c|c|c|}
\hline No. of episodes of OM & $\begin{array}{c}\geq 1 \\
(n=76)\end{array}$ & $\begin{array}{c}\geq 2 \\
(n=55)\end{array}$ & $\begin{array}{c}\geq 3 \\
(n=38)\end{array}$ & $\begin{array}{c}\geq 4 \\
(n=26)\end{array}$ & $\begin{aligned} & \geq 5 \\
(n & =17)\end{aligned}$ & $\begin{array}{c}\mathrm{ROM} \\
(n=28)\end{array}$ \\
\hline $\begin{array}{l}\text { Day care outside the home at age } \\
\text { of } 12.0 \mathrm{mo}\end{array}$ & $\begin{array}{c}1.7 \\
(1.2-2.3)\end{array}$ & $\begin{array}{c}1.6 \\
(1.1-2.3)\end{array}$ & $\begin{array}{c}1.9 \\
(1.3-3.0)\end{array}$ & $\begin{array}{c}1.8 \\
(1.1-3.0)\end{array}$ & $\begin{array}{c}1.7 \\
(1.0-2.8)\end{array}$ & $\begin{array}{c}1.9 \\
(1.1-3.2)\end{array}$ \\
\hline Occurrence of own atopic disease & & & & & $\begin{array}{c}2.2 \\
(1.2-4.2)\end{array}$ & $\begin{array}{c}1.9 \\
(1.2-3.2)\end{array}$ \\
\hline
\end{tabular}

* Relative risk is given only where significantly $>1.0$. The other 13 variables in Table 1 were not significant risk factors for OM or its recurrence.

Table 3. Feeding parameters in infants with ROM and in the infants without OM; median and 1st and 3rd quartiles are given for age in days*

\begin{tabular}{lccc}
\hline & $\begin{array}{c}\text { Infants with } \\
\text { early-onset } \\
\text { ROM } \\
(n=12)\end{array}$ & $\begin{array}{c}\text { Infants with } \\
\text { 2nd-yr ROM } \\
(n=16)\end{array}$ & $\begin{array}{c}\text { Infants } \\
\text { without OM } \\
(n=80)\end{array}$ \\
\hline $\begin{array}{c}\text { First exposure to } \\
\text { cow's milk }\end{array}$ & $242(78-258)$ & $98(36-281)$ & $240(82-291)$ \\
$\begin{array}{c}\text { Start of regular } \\
\text { formula feeding }\end{array}$ & $242(180-278)$ & $258(80-290)$ & $251(111-294)$ \\
$\begin{array}{c}\text { Complete weaning } \\
\text { from breast }\end{array}$ & $335(186-404)$ & $238(98-347)$ & $286(111-354)$ \\
$\begin{array}{c}\text { Introduction of } \\
\text { solid foods }\end{array}$ & $185(133-233)$ & $176(132-239)$ & $190(134-235)$ \\
\hline
\end{tabular}

* There were no statistically significant differences between these groups, or between all infants with and those without ROM.

Table 4. Prevalence of exclusive breast-feeding among infants with ROM and infants without $O M^{*}$

\begin{tabular}{cccc}
\hline & $\begin{array}{c}\text { Infants with } \\
\text { early-onset } \\
\text { ROM } \\
(n=12)\end{array}$ & $\begin{array}{c}\text { Infants with } \\
\text { 2nd-yr } \\
\text { ROM } \\
(n=16)\end{array}$ & $\begin{array}{c}\text { Infants } \\
\text { without OM } \\
(n=80)(\%)\end{array}$ \\
\hline Age (mo) & 92 & $(\%)$ & 81 \\
2 & 58 & 75 & 60 \\
9 & 0 & 50 & 18 \\
\hline
\end{tabular}

* There were no statistically significant differences between these groups or even between all infants with and without ROM.

Cow's milk antibodies. The mean levels of IgG cow's milk antibodies were similar in the ROM group and the comparison group. At 12 months of age a higher proportion of infants with ROM than of the comparison group ( 22 versus $6 \%, p<0.05$ ) had supranormal ( $>2.0 \mathrm{SD}$ ) levels of IgG cow's milk antibodies. At 9 months of age the infants with early-onset ROM had a higher mean level of IgM cow's milk antibodies than the infants with 2 nd-yr ROM (58 versus $12 \%$, of the standard plasma, $p<$ $0.05)$.

Socioeconomic background. The group with ROM did not differ from the comparison group in the educational level of the mother or the economic status of the family. The mean absolute and relative size of the home was similar, as was the mean size of the family.

Number of child contacts and day-care. The number of daily child contacts during the 2 nd yr was a predictive factor for ROM. The relative risk was 2.1 (Table 1 ) if the number of child contacts was five or more. During their 2 nd yr the infants with 2 nd-yr ROM had daily contacts with a mean of 11 versus five children for the infants with early-onset ROM and five for the comparison group $(p<0.001)$. Daycare outside the home at the age of 1.0 yr was also a risk factor for ROM (Table 1), even for the first episode of OM (Table 2). The proportion of infants having daycare outside the home during both their 1 st and 2 nd yr was higher among the infants with ROM than among those of the comparison group (59 and $69 \%$ versus 24 and $44 \% ; p<0.05$ ). The same was true for those attending a daycare center during their 2 nd year ( 44 versus $18 \%, p<0.05$ ). However, 10 of the 12 infants with early-onset $O M$ had the first $O M$ when still being taken care of at home. Ten of 16 infants with 2 nd-yr ROM had daycare outside the home when OM presented.

Smoking and pets. Of the parents, 55\% smoked in the ROM group versus $33 \%$ in the comparison group $(p<0.05)$. There was no such significant difference between the groups in the proportion of homes with a pet (16 versus $20 \%$ ).

\section{DISCUSSION}

We noticed a rapid increase in the incidence of OM from $22 \%$ during the infants' 1 st yr to $48 \%$ during their $2 \mathrm{nd}$ yr. The incidence of $\mathrm{OM}$ is highest during the first $2 \mathrm{yr}$ of life $(1-2,18)$. Our values were close to those reported $(2,3,18)$. There are no accepted criteria for ROM; our definition (five or more episodes during the first 2 yr or four or more during the 2 nd yr) resulted in an incidence of $15 \%$. A similar incidence $(13 \%)$ was found in another Finnish study (3), but much higher values (30\%) have been reported $(1,2)$.

We found different risk factors in infants with early-onset and 2nd-yr ROM. Most of the infants with early-onset ROM had atopy and the mean plasma level of IgE was higher in these infants than in the infants with 2nd yr ROM and those without OM. This association with atopy has been noted earlier in regard to secretory $\operatorname{OM}(19,20)$, but has recently been disputed $(3,21)$. The majority of infants with early-onset ROM were partially or exclusively breast-fed, were cared for at home, and had a small number of daily child contacts at the time of the first episode of OM. In contrast, the infants with 2nd-yr ROM did not differ from the comparison group in the frequency of atopy. They had a large number of daily child contacts and were taken care outside the home during the 2 nd yr of life; these were significant risk factors for ROM and for the recurrence.

Smoking by the parents may irritate the respiratory mucosa and so predispose to $\operatorname{ROM}(7,18,23)$ but today parents seem to be aware of this risk and avoid smoking at home or at least in the vicinity of the infant. Although parental smoking was not a risk factor for ROM, there were more smokers among parents of the infants with ROM than in the comparison group.

In our prospective study we tried to control and record all known confounding factors and we had detailed information about the feeding of the infants. We could study the simultaneous effect of many factors and identify independent risk factors for ROM by logistic regression analysis. These turned out to include no feeding variables. The mean durations of exclusive breastfeeding and of breast-feeding in general were similar in the infants with ROM and the comparison group. Thus prolongation of exclusive breast-feeding does not seem to afford added protection. All the infants were initially breast-fed and may have benefitted from this concerning the propensity toward ROM. 
Table 5. Plasma IgE concentrations (IU/ml) in infants with early-onset and 2 nd-yr ROM and infants without OM (geometric mean and $95 \%$ confidence limits are given)

\begin{tabular}{|c|c|c|c|c|c|c|}
\hline \multirow[b]{2}{*}{ Series } & \multicolumn{2}{|c|}{ IgE } & \multirow[b]{2}{*}{ IgE at $9 \mathrm{mo}$} & \multirow[b]{2}{*}{$n$} & \multicolumn{2}{|c|}{$\operatorname{IgE}$} \\
\hline & at $6 \mathrm{mo}$ & $n$ & & & at $12 \mathrm{mo}$ & $n$ \\
\hline $\begin{array}{l}\text { Infants with early-on- } \\
\text { set ROM }\end{array}$ & $3.2(1.3-7.9)$ & 12 & $5.5(1.6-18.7)$ & 9 & $\begin{array}{c}10.8(3.9-30.0) \\
+\end{array}$ & 12 \\
\hline $\begin{array}{l}\text { Infants with 2nd-yr } \\
\text { ROM }\end{array}$ & $1.3(0.5-3.1)$ & 8 & $1.3(0.6-2.9)$ & 10 & $1.8(0.7-4.7)$ & 12 \\
\hline Infants without $\mathrm{OM}$ & $3.3(2.2-5.0)$ & 63 & $3.9(1.8-8.0)$ & 65 & $6.1(4.3-8.8)$ & 77 \\
\hline
\end{tabular}

Significant differences between groups are indicated; ${ }^{*} p<0.05 ; \uparrow p<0.01$.

However, our study does not allow an evaluation of benefits of early breast-feeding. Neither short nor prolonged breast-feeding were risk factors for infantile atopy in our series (16). The total level of IgA was lower in the milk of the mothers whose infants became allergic to cow's milk than in mothers with nonallergic infants (24). Thus the quality of the breast milk may be more important in conferring resistance to disease than the duration of breast-feeding.

Cow's milk has been claimed to cause recurrence of OM in infancy either as an allergen (9) or as a direct irritant of the nasopharyngeal tubes in horizontal feeding (6). OM was more common in the infants with CMA than in the others, but only one of the infants with CMA developed ROM. Probably early detection of CMA with subsequent elimination diet and otorhinologic operations averted the cycle of infections. Another finding suggesting that cow's milk plays a role in ROM in some infants is the increased level of IgM antibodies to cow's milk in the plasma of these infants and the increased prevalence of supranormal levels of IgG antibody to cow's milk.

Our findings indicate that infantile ROM is associated with a number of predisposing factors. In some infants immune reactions are associated with cow's milk feeding. In infants developing ROM the most important risk factor in the 1st yr. was their own atopy, in contrast to daycare outside the home and a large number of child contacts in the 2 nd yr.

Acknowledgment. The formula was kindly donated by Valio Co. Ltd., Helsinki, Finland and canned solid foods (given to some infants as a supplement to breast-feeding) by Orion Co., Chymos, Lappeenranta, Finland.

\section{REFERENCES}

1. Bluestone CD, Klein JO 1983 Otitis media with effusion, atelectasis and Eustachian tube dysfunction. In: Bluestone CD (ed) Pediatric Otolaryngology. WB Saunders CO, Philadelphia, pp 356-512

2. Teele DW, Klein JO, Rosner BA 1980 Epidemiology of otitis media in children. Ann Otol Rhinol Laryngol 89(suppl 65):5-8

3. Saarinen UM 1982 Prolonged breast feeding as prophylaxis for recurrent otitis media. Acta Paediatr Scand 71:567-571
4. Strangert K 1977 Otitis media in young children in different types of day-care. Scand J Infect Dis 9:119-123

5. Bluestone $C D 1978$ Eustachian tube function and allergy in otitis media. Pediatrics 61:753-760

6. Duncan RB 1960 Positional otitis media. Arch Otolaryngol 72:454-463

7. Vinther B, Elbrond O, Pedersen CB 1979 A population study of otitis media in childhood. Acta Otolaryngol 360(suppl):135-137

8. Kjellman N-IM, Synnerstad B, Hansson LO 1976 Atopic allergy and immunoglobulins in children with adenoids and recurrent otitis media. Acta Paediatr Scand 65:593-600

9. Jordan RE 1960 Allergy of middle ear and inner ear. Arch Otolaryngol 71:212215

10. Chandra RK 1979 Prospective studies of the effect of breast feeding on the incidence of infection and allergy. Acta Paediatr Scand 68:691-694

11. Cunningham AS 1979 Morbidity in breast-fed and artificially fed infants II. J Pediatr 95:685-689

12. Teele DW, Klein JO, Rosner B 1980 Beneficial effects of breast feeding on duration of middle ear effusion after first episode of acute otitis media. Pediatr Res 14:494 (abstr)

13. Paine R, Coble RJ 1982 Breast-feeding and infant health in a rural US community. Am J Dis Child 136:36-38

14. Kovar MG, Serdula MK, Marks JS, Fraser DW 1984 Review of the epidemiologic evidence for an association between infant feeding and infant health. Pediatrics 74:615-638

15. Salmenpera L, Perheentupa J, Siimes MA 1985 Exclusively breast-fed healthy infants grow slower than reference infants. Pediatr Res 19:307-312

16. Savilahti E, Tainio V-M, Salmenpera L, Siimes MA, Perheentupa J 1987 Prolonged exclusive breast feeding and heredity as determinants in infantile atopy. Arch Dis Child 62:269-273

17. Savilahti E, Salmenpera L, Tainio V-M, Halme H, Perheentupa J, Siimes MA 1987 Prolonged exclusive breast-feeding results in low serum concentrations of immunoglobulin G, A and M. Acta Paediatr Scand 76:1-6

18. Pukander J 1982 Acute otitis media among rural children in Finland. Int $J$ Pediatr Otorhinolaryngol 4:325-332

19. Reisman RE, Bernstein J 1975 Allergy and secretory otitis media. Clinical and immunological studies. Pediatr Clin North Am 22:251-257

20. Viscomi GJ 1975 Allergic secretory otitis media: an approach to management. Laryngoscope 85:751-758

21. Stempel DA, Wallace AC, Henderson FW, Collier AM 1980 Serum IgE levels and the clinical expression of respiratory illness. J Pediatr 97:185-190

22. Ståhlberg M-R 1980 The influence of form of day care on occurrence of acute respiratory tract infections among young children. Acta Paediatr Scand 282(suppl):1-80

23. Bland M, Bewley RB, Pollard V, Banks MH 1978 Effect of children's and parent's smoking on respiratory symptoms. Arch Dis Child 53:100-105

24. Savilahti E, Salmenperä L, Tainio V-M, Arjomaa P, Siimes MA, Perheentupa J 1987 Mothers of infants with cow's milk allergy vs controls have less IgA antibodies to cow's milk protein in milk. Pediatr Res 22:99 (abstr) 